\title{
Associations of adult-attained height and early life energy restriction with postmenopausal breast cancer risk according to estrogen and progesterone receptor status
}

Citation for published version (APA):

Elands, R. J. J., Offermans, N. S. M., Simons, C. C. J. M., Schouten, L. J., Verhage, B. A., van den Brandt, P. A., \& Weijenberg, M. P. (2019). Associations of adult-attained height and early life energy restriction with postmenopausal breast cancer risk according to estrogen and progesterone receptor status. International Journal of Cancer, 144(8), 1844-1857. https://doi.org/10.1002/ijc.31890

Document status and date:

Published: 15/04/2019

DOI:

10.1002/ijc.31890

Document Version:

Publisher's PDF, also known as Version of record

Document license:

Taverne

Please check the document version of this publication:

- A submitted manuscript is the version of the article upon submission and before peer-review. There can be important differences between the submitted version and the official published version of record. People interested in the research are advised to contact the author for the final version of the publication, or visit the DOI to the publisher's website.

- The final author version and the galley proof are versions of the publication after peer review.

- The final published version features the final layout of the paper including the volume, issue and page numbers.

Link to publication

\footnotetext{
General rights rights.

- You may freely distribute the URL identifying the publication in the public portal. please follow below link for the End User Agreement:

www.umlib.nl/taverne-license

Take down policy

If you believe that this document breaches copyright please contact us at:

repository@maastrichtuniversity.nl

providing details and we will investigate your claim.
}

Copyright and moral rights for the publications made accessible in the public portal are retained by the authors and/or other copyright owners and it is a condition of accessing publications that users recognise and abide by the legal requirements associated with these

- Users may download and print one copy of any publication from the public portal for the purpose of private study or research.

- You may not further distribute the material or use it for any profit-making activity or commercial gain

If the publication is distributed under the terms of Article 25fa of the Dutch Copyright Act, indicated by the "Taverne" license above, 


\title{
Associations of adult-attained height and early life energy restriction with postmenopausal breast cancer risk according to estrogen and progesterone receptor status
}

\author{
Rachel J. J. Elands (i) ${ }^{1}$, Nadine S. M. Offermans ${ }^{1}$, Colinda C. J. M Simons ${ }^{(1)^{1}}$, Leo J. Schouten ${ }^{1}{ }^{1}$, Bas A. Verhage ${ }^{1}$, \\ Piet A. van den Brandt $\mathbb{D}^{1,2}$ and Matty P. Weijenberg ${ }^{1}$ \\ ${ }^{1}$ Department of Epidemiology, GROW - School for Oncology and Developmental Biology, Maastricht University, Maastricht, the Netherlands \\ ${ }^{2}$ Department of Epidemiology, CAPHRI - School for Public Health and Primary Care, Maastricht University Medical Centre, Maastricht, the Netherlands
}

\begin{abstract}
Adult-attained height is a marker for underlying mechanisms, such as cell growth, that may also influence postmenopausal breast cancer $(B C)$ risk, perhaps specifically hormone-sensitive $B C$ subtypes. Early life energy restriction may inhibit these mechanisms, resulting in shorter height and a reduced postmenopausal BC risk. Women $(62,573)$ from the Netherlands Cohort Study completed a self-administered questionnaire in 1986 when 55-69 years old, and were followed-up for 20.3 years (casecohort: $N_{\text {subcohort }}=2,438 ; N_{\text {cases }}=3,354$ ). Cox multivariable-adjusted hazard ratios (HR) and $95 \%$ confidence intervals $(\mathrm{Cl})$ were estimated for $\mathrm{BC}$ risk overall and by estrogen and progesterone receptor subtypes in relation to height and early life energy restriction during the Hunger Winter, War Years, and Economic Depression. Although energy restriction can only influence longitudinal growth in women exposed before and/or during the growth spurt, it may also influence $B C$ risk when occurring after the growth spurt, possibly through different growth processes. Therefore, Cox analyses were additionally conducted according to timing of energy restriction in relation to the growth spurt. Height was associated with an increased $\mathrm{BC}$ risk $\left(\mathrm{HR}_{\text {per } 5 \mathrm{~cm}}=1.07,95 \% \mathrm{Cl}: 1.01-1.13\right)$, particularly hormone receptor-positive $B C$. Energy restriction before and/or during the growth spurt was associated with a decreased hormone receptor-positive $B C$ risk. Energy restriction during the Hunger Winter increased the estrogen receptor-negative $B C$ risk regardless of the timing of energy restriction. In conclusion, height and energy restriction before and/or during the growth spurt were both associated with hormone receptor-positive BC risk, in the direction as expected, indicating critical exposure windows for hormonal growth-related mechanisms.
\end{abstract}

\section{Introduction}

Based on meta-analyses from cohort studies, there is convincing evidence that postmenopausal breast cancer (BC) risk is increased by $7-11 \%$ for every $5 \mathrm{~cm}$ increase in adult-attained height. $^{1-3}$ This may be of particular relevance for the tallest population in the world, the population of the Netherlands, ${ }^{4}$ which also has one of the highest $\mathrm{BC}$ rates worldwide. ${ }^{5}$ While information on BC hormone receptor status is not always available, associations between adult-attained height and

Key words: breast cancer epidemiology, adult-attained height, energy restriction, estrogen receptor status, progesterone receptor status Additional Supporting Information may be found in the online version of this article.

Grant sponsor: WCRF-NL; Grant numbers: 2012/618

DOI: $10.1002 / \mathrm{ijc} .31890$

History: Received 25 Feb 2018; Accepted 18 Jul 2018;

Online 25 Sep 2018

Correspondence to: Matty P. Weijenberg, Department of Epidemiology; Maastricht University; P.O. Box 616,

6200 MD Maastricht, the Netherlands, E-mail:

mp.weijenberg@maastrichtuniversity.nl; Tel.: +31 433882 358;

Fax: +31646705068 postmenopausal BC risk may exist particularly for the most commonly diagnosed breast cancer subtype, which is the estrogen receptor positive $(\mathrm{ER}+)$ subtype. Associations of adult-attained height with $\mathrm{ER}+\mathrm{BC}$ have been reported both in combination with $\mathrm{PR}+\mathrm{BC}^{6,7}$ and when studied separately as an endpoint (i.e., no information on $\mathrm{PR}$ status was available). ${ }^{8-10}$ Significantly increased $\mathrm{ER}+\mathrm{BC}$ relative risks have been reported in association with adult-attained height and null associations have been reported for ER-BC risk, ${ }^{8,9}$ when ER status is studied regardless of PR status as an endpoint. Joint $\mathrm{ER}+\mathrm{PR}+\mathrm{BC}$ status has been associated with increased relative risks in relation to adult-attained height, ${ }^{6,7}$ whereas joint ER-PR- BC status has been associated both with increased relative risks ${ }^{7}$ and null associations. ${ }^{6}$ There is only one study that investigated adult-attained height in relation to $\mathrm{PR}+$ tumors as a separate endpoint, which reported associations with nonsignificant increased relative risks for both $\mathrm{PR}+$ and PR- BC status. ${ }^{8}$ The inconclusive findings for adultattained height and hormone-receptor negative subtypes, that is, both null associations and nonsignificantly increased relative risks, may be due to the fact that BCs with a negative hormone receptor status are less common, resulting in relatively less power to investigate these subtypes, and that information 
What's new?

Evidence suggests that postmenopausal breast cancer risk increases with height, while risk is reduced among individuals who experience reduced caloric intake in early life, which can result in shorter adult stature. In this investigation of women in the Netherlands Cohort Study, significant early-life energy restriction, either before or during the pubertal growth spurt, was associated specifically with a decreased risk of estrogen receptor-positive and progesterone receptor-positive postmenopausal breast cancer. Greater adult-attained height was significantly associated with increased hormone receptor-positive postmenopausal breast cancer risk. The findings highlight the influence of hormonal growth-related mechanisms on later postmenopausal breast cancer risk.

on PR BC status is less often available than ER BC status, limiting opportunities to investigate this. Yet, it is also plausible that there is a null association between adult-attained height and hormone receptor-negative $\mathrm{BC}$.

Adult-attained height is a marker for mechanisms such as cell growth, which determine both adult-attained height and postmenopausal BC risk. These growth processes can be influenced by early life environmental exposures. ${ }^{11,12}$ Therefore, when energy balance is disturbed in early life, for example, by energy restriction, this can have an effect on adult-attained height and postmenopausal BC risk later in life. In a recent meta-analysis of observational studies by our group, severe transient energy restriction during early life was associated with a $28 \%$ increased BC risk, though some of the underlying studies showed null results. ${ }^{13}$ Conversely, moderate energy restriction during early life for a longer period of time, as studied in animal experimental models and human ecological studies, was generally inversely associated with $\mathrm{BC}$ risk. ${ }^{13}$ Biologically, the latter seems plausible as continuous moderate early life energy restriction (pre- and peripubertal) may lead to decreased growth factor levels, ${ }^{14}$ which in turn may result in a shorter stature ${ }^{15-17}$ and a reduced postmenopausal BC risk. ${ }^{18}$ Earlier and more rapid childhood and pubertal growth, for instance during catch-up growth, on the other hand, appear to increase postmenopausal BC risk. ${ }^{19-22}$ In our metaanalysis, results from a sub analysis on energy restriction in women aged $10-20$ years indicated a $21 \%$ increased BC risk compared to women not exposed during that age period. A comparison with the summary risk estimate in women aged 0-10 years was not possible, however, as this estimate could not be computed due to a high between-study heterogeneity. ${ }^{13}$ One source of heterogeneity in results may be differences in distribution of hormone receptor subtypes among BC cases. To our knowledge, only one report has been published on the association between energy restriction and postmenopausal $\mathrm{BC}$ risk by $\mathrm{ER}+/-$ and $\mathrm{PR}+/$ - status, investigating combinations of $\mathrm{ER}+/$ - and $\mathrm{PR}+/$ - subtypes. ${ }^{23}$ Results of our study showed that women exposed to the Chinese famine, particularly those exposed after birth (0-3 years), had an increased risk of $\mathrm{ER}-\mathrm{PR}-\mathrm{BC}, \mathrm{ER}-\mathrm{PR}+\mathrm{BC}$, and $\mathrm{ER}+\mathrm{PR}-\mathrm{BC}$, while no association was observed with $\mathrm{ER}+\mathrm{PR}+\mathrm{BC}$.

The Netherlands Cohort Study (NLCS), a prospective cohort study that includes 58,279 men and 62,573 women, has data available on height, early life energy restriction, $\mathrm{ER}+/$ - and $\mathrm{PR}+/$ - status of breast cancer cases during followup and other covariates. The long follow-up of 20.3 years enabled us to study the following aims with sufficient power. Firstly, we investigated the association of adult-attained height with overall postmenopausal $\mathrm{BC}$ risk and by $\mathrm{ER}+/$ - and $\mathrm{PR}+/$ status of the tumor. Secondly, we examined the association of early life energy restriction with overall postmenopausal BC risk and by $\mathrm{ER}+/$ - and $\mathrm{PR}+/$ - status of the tumor. Considering that different growth processes may be at play during different periods in life, we additionally conducted these analyses according to timing of energy restriction in relation to the growth spurt. Energy restriction was hypothesized to be able to affect longitudinal growth only when exposure occurred before and/or during the growth spurt, but an effect on BC risk could also exist for exposure after the growth spurt, and not necessarily through a relationship between energy restriction and height. The association between adult-attained height and early life energy restriction with regard to breast cancer risk has been studied in the NLCS previously. A positive association between adult-attained height and breast cancer risk among postmenopausal women was observed, after 4.3 years of follow-up. ${ }^{24}$ With regard to energy restriction, neither exposure to early life energy restriction regardless of timing of the growth spurt nor exposure to energy restriction during the adolescent growth spurt were associated with breast cancer risk after 6.3 years of follow-up. ${ }^{25}$

\section{Methods \\ Study population and design}

The Netherlands Cohort Study (NLCS) includes 58,279 men and 62,573 women, who were 55 to 69 years old at baseline in September $1986 .^{26}$ Participants completed a self-administered questionnaire at baseline on cancer risk factors. For efficiency reasons related to the processing of questionnaires and followup, the NLCS uses a case-cohort design in which cases are enumerated from the entire cohort and the person-time at risk is estimated from a subcohort. This subcohort, consisting of 5,000 men and women, was randomly selected immediately after baseline and independent of exposure. The follow-up for vital status and migration is performed through linkage to the Central Bureau of Genealogy and the municipal population registries $(\sim 100 \%$ completeness $){ }^{27}$ Cancer follow-up is 
Table 1. Overview of the overlap between hormone receptor subtypes of breast cancer in postmenopausal women of the Netherlands Cohort Study

\begin{tabular}{|c|c|c|c|c|}
\hline & $\mathrm{PR}+\mathrm{BC}$ cases & PR- BC cases & $\begin{array}{l}\text { BC cases with } \\
\text { unknown PR status }\end{array}$ & \\
\hline & N (\%) & N (\%) & N (\%) & $\begin{array}{l}\text { Total number of } B C \\
\text { cases by } E R \text { status }\end{array}$ \\
\hline $\mathrm{ER}+\mathrm{BC}$ cases & $979(97,0 \%)$ & $308(55,4 \%)$ & $333(18,6 \%)$ & 1,620 \\
\hline ER- BC cases & $30(3,0 \%)$ & $245(44,1 \%)$ & $89(5,0 \%)$ & 364 \\
\hline $\mathrm{BC}$ cases with unknown ER status & $0(0,0 \%)$ & $3(0,5 \%)$ & $1,367(76,4 \%)$ & 1,370 \\
\hline Total number of BC cases by PR status & 1,009 & 556 & 1,789 & 3,354 \\
\hline
\end{tabular}

Abbreviation: BC, breast cancer; ER+, estrogen receptor positive; ER-, estrogen receptor negative; PR+, progesterone receptor positive; PR-, progesterone receptor negative.

performed through linkage to the population-based cancer registry and PALGA (Netherlands pathology database; >95\% completeness).$^{28}$ Participants who reported a history of cancer at baseline (except skin cancer) were excluded leaving 4,774 subcohort members, of which 2,438 female subcohort members. A total of 3,354 postmenopausal BC cases were identified in the total cohort after 20.3 years of follow-up (September
17, 1986, until January 1, 2007) (ICD-O-3: C50). ER and PR receptor status was available for $59 \%$ and $47 \%$ of the cases, respectively, with 1,620 ER+ cases, $364 \mathrm{ER}$ - cases, 1,009 PR+ cases, and 556 PR- cases (see Table 1 for an overview of the overlap between hormone receptor subtypes). If dietary data of participants were incomplete or inconsistent, these participants were excluded, leaving 2,248 female subcohort members

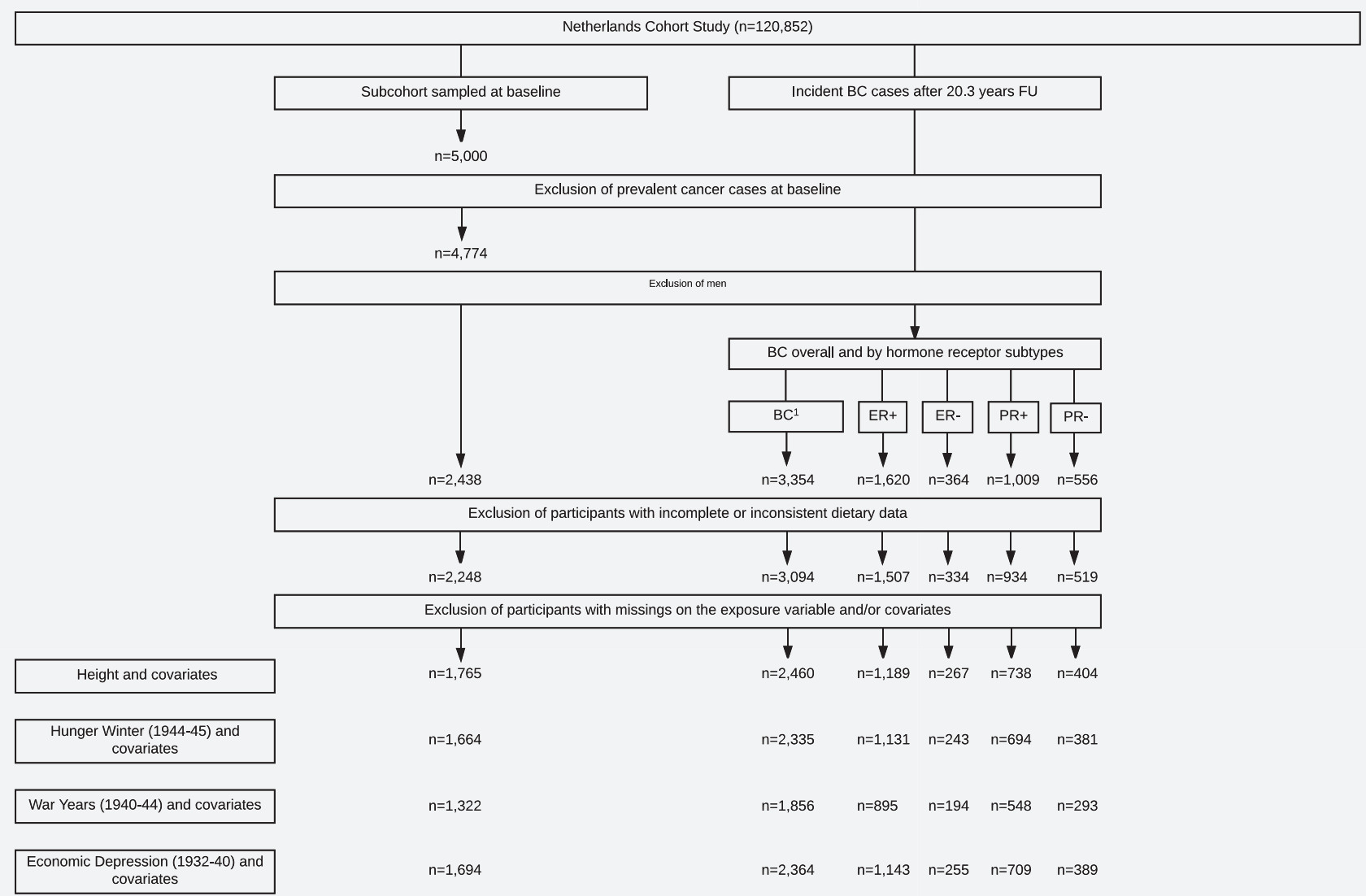

Abbreviations: BC, breast cancer; FU, follow-up; ER+, estrogen receptor positive; ER-, estrogen receptor negative; PR+, progesterone receptor positive; PR-, progesterone receptor negative ${ }^{1}$ The sum of cases of the different $\mathrm{BC}$ subtypes differs from the total number of $\mathrm{BC}$ cases as hormone receptor status was not known for all BC cases.

Figure 1. Flow diagram of available subcohort members and breast cancer cases among postmenopausal women in the Netherlands Cohort Study, 1986-2006. 
and 3,094 postmenopausal BC cases, among which 1,507 ER+ cases, 334 ER- cases, $934 \mathrm{PR}+$ cases, and $519 \mathrm{PR}$ - cases (see flow chart in Fig. 1).

\section{Exposure assessment}

Adult-attained height $(\mathrm{cm})$ was self-reported on the baseline questionnaire. Height was defined as a continuous variable (per $5 \mathrm{~cm}$ increase) as well as a categorical variable in tertiles based on the distribution in the female subcohort. Early life energy restriction was measured through three proxy variables, as individual food intake data in early life of the cohort members were not available. The proxies covered three time periods in the Netherlands during which a part of the population experienced energy restriction, that is, the Hunger Winter (the winter of 1944-45), the War Years (1940-44), and the Economic Depression (1932-40). For the Hunger Winter, which was at its height between December 1944 and May 1945, place of residence was used to approximate exposure to energy restriction as individuals living in a western city, and to a lesser extent a western rural area, were exposed to (severe) energy restriction. During this time period, official daily rations per capita were between 400 and $800 \mathrm{kcal}$ for women living in a western city. ${ }^{29,30}$ In a follow-up study in the NLCS, female subcohort members were asked if they really had experienced hunger during the Hunger Winter. Of the women who reported severe hunger, $80 \%$ lived in a western city during this winter. ${ }^{25}$ These results indicate that place of residence during the Hunger Winter is an adequate proxy for exposure to energy restriction. Place of residence was based on the reported residence during the winter of 1944-45 and classified into "living in a nonwestern area," "living in a western rural area," or "living in a western city." Also for the War Years, place of residence was used as a proxy for energy restriction. During the War Years, food rationing was introduced, and caloric intake was reduced to $\sim 1,700 \mathrm{kcal} / \mathrm{d}$ during 1941-1943. ${ }^{31}$ Between 1943 and 1944, the nutritional status of the Dutch population deteriorated, especially for those living in the cities. ${ }^{25}$ Place of residence was based on the question to list the last 4 residences before baseline of the study, which resulted in a classification into "living in an urban area" (defined as a town with at least 40,000 residents) or "living in a rural area" in 1942 (the midpoint of the War Years 1940-44). For the Economic Depression, employment status of the father was used to approximate exposure to energy restriction. Several surveys showed that having an unemployed father indicated that the number of calories available was less and the variation in the individual's food pattern was limited compared to families with an employed father. ${ }^{25,32}$ Father's employment status was dichotomized into participants whose father had a job during the years of the Economic Depression or worked intermittingly ("employed") and cohort members with fathers without a job during these years ("unemployed"). ${ }^{33}$ Information on covariates that were considered potential confounders on the basis of previous research was also available from the baseline questionnaire.

\section{Statistical analyses}

We calculated the mean adult-attained height for each category of the three proxies for early life energy restriction in those female subcohort members exposed to energy restriction before and/or during the growth spurt, since we only expected an effect of energy restriction on mean adultattained height in this subgroup of women. The historic events that are associated to the three proxies took place in three different periods in time and thus affected cohort members at different ages (12-28 years for the Hunger Winter, 7-28 years for the War Years, and 0-23 years for the Economic Depression). The growth spurt was defined as two years before the self-reported age at menarche until one year after the reported age at menarche. Furthermore, in a sensitivity analysis, we restricted the analyses for the Hunger Winter and the War Years to individuals from the middle provinces of the Netherlands. We did so, because there was virtually no exposure to energy restriction in the northern and southern provinces during both time periods, as these are mostly nonwestern and rural areas, and, at the same time, these provinces are characterized by, on average, the tallest and shortest people in the country, respectively. ${ }^{4}$ Including individuals from these provinces in the analyses, therefore, can mask the relationship between energy restriction and height, if present. Cox proportional hazards analysis was used to estimate both age-adjusted and multivariableadjusted hazard ratios (HRs) and 95\% confidence intervals (CIs) for postmenopausal BC risk overall and by $\mathrm{ER}+/-$ and $\mathrm{PR}+/$ - status. In the multivariable-adjusted models, we adjusted for potential confounders that were selected a priori on the basis of that these were risk factors in the literature. To account for the additional variance introduced by sampling the subcohort from the entire cohort, standard errors were estimated using the robust Huber-White sandwich estimator. ${ }^{34}$ The proportional hazards assumption was tested using the scaled Schoenfeld residuals and by visual inspection of the $-\log (-\log )$ transformed hazard curves. ${ }^{35}$

In the multivariable-adjusted models for height and postmenopausal BC risk, the following a priori selected potential confounders were included on the basis of that these are potential risk factors for postmenopausal BC: age at baseline (y), energy intake $(\mathrm{kcal} / \mathrm{d})$, baseline nonoccupational physical activity $(\leq 30 \mathrm{~min} / \mathrm{d},>30-\leq 60 \mathrm{~min} / \mathrm{d},>60-90 \mathrm{~min} / \mathrm{d}$, $>90 \mathrm{~min} / \mathrm{d}$ ), smoking status (never, former, current), smoking frequency (numbers of cigarettes per day; continuous, centered), and smoking duration (number of years; continuous, centered), alcohol intake $(0,0.1-29, \geq 30 \mathrm{~g} / \mathrm{d})$, level of education (primary school, lower vocational school, intermediate vocational/high school, higher vocational school/ university), family history of BC (no, yes), history of benign breast disease (no, yes), age at menarche (y), age at menopause (y), age at first childbirth (nulliparous, $>25 \mathrm{y}, \leq 25 \mathrm{y}$ ), parity ( $n$ children), oral contraceptive use (never, ever), and postmenopausal hormone-replacement therapy (never, ever). After excluding 
participants without (complete) information on height and/or the covariates, 1,765 subcohort members and 2,460 postmenopausal BC cases were left for analysis (see Fig. 1).

Considering that (most) other studies that have investigated the height-BC association have not adjusted for body mass index (BMI) $\left(\mathrm{kg} / \mathrm{m}^{2}\right)$ or weight $(\mathrm{kg})$, our primary model will not include BMI or weight, enabling comparison of our results with those in the literature. BMI approximates body fatness, though may do so differentially depending on age and height, with a positive correlation between height and BMI in young populations and an inverse correlation in older populations. ${ }^{36,37}$ Since the NLCS comprises an older population, we conducted two additional sensitivity analyses to investigate whether including either BMI or weight as additional continuous covariates in the models for height changed the associations.

In the multivariable-adjusted models for early life energy restriction and postmenopausal BC risk, the following a priori selected potential confounders were included on the basis of that these are potential risk factors for postmenopausal BC: age at baseline $(\mathrm{y})$, BMI $\left(\mathrm{kg} / \mathrm{m}^{2}\right)$, energy intake $(\mathrm{kcal} / \mathrm{d})$, baseline nonoccupational physical activity $(\leq 30 \mathrm{~min} / \mathrm{d},>30-\leq 60 \mathrm{~min} / \mathrm{d}$, $>60-90 \mathrm{~min} / \mathrm{d},>90 \mathrm{~min} / \mathrm{d}$ ), smoking status (never, former, current), smoking frequency (numbers of cigarettes per day; continuous, centered), smoking duration (number of years; continuous, centered), alcohol intake (0, 0.1-29, $\geq 30 \mathrm{~g} / \mathrm{d})$, level of education (primary school, lower vocational school, intermediate vocational/high school, higher vocational school/ university), family history of BC (no, yes), history of benign breast disease (no, yes), age at menopause (y), age at first childbirth (nulliparous, $>25 \mathrm{y}, \leq 25 \mathrm{y}$ ), parity ( $n$ children), oral contraceptive use (never, ever), and postmenopausal hormonereplacement therapy (never, ever). In a sensitivity analysis, we checked whether additional adjustment for adult-attained height and age at menarche changed the results because these are also important risk factors for postmenopausal BC. However, early life energy restriction may also influence adultattained height and age at menarche and these could thus also act as intermediate factors. After excluding participants without (complete) information on energy restriction and/or the primary covariates of interest, 1,664 subcohort members and 2,335 postmenopausal BC cases were left for analysis for the Hunger Winter, 1,322 subcohort members and 1,856 postmenopausal BC cases left for analysis for the War Years, and 1,694 subcohort members and 2,364 postmenopausal BC cases for the Economic Depression (see Fig. 1).

\section{Results}

Table 2 shows baseline characteristics of the female subcohort members and postmenopausal $\mathrm{BC}$ cases overall and by hormone receptor subtypes. Postmenopausal BC cases, in particular $\mathrm{ER}+$ and $\mathrm{PR}+$ cases, more often reported a family history of $\mathrm{BC}$ compared to subcohort members. Additionally, postmenopausal BC cases more often reported a history of benign breast disease compared to subcohort members.

Mean adult-attained height according to early life energy restriction. Table 3 shows the mean adult-attained height by exposure to early life energy restriction in female subcohort members who were exposed to energy restriction before and/or during the growth spurt, and when further restricting to female subcohort members living in the middle provinces of the Netherlands. There were no differences in height between female subcohort members who were and those who were not exposed to energy restriction before and/or during the growth spurt as a result of the Hunger Winter or the War Years. Further restriction of the analyses to those living in the middle provinces of the Netherlands did not change this finding. During the Economic Depression, most of the women from the cohort were younger (0-23 years) and most (94.4\%) were before or in their growth spurt. Female subcohort members who were exposed to energy restriction during the Economic Depression before or during their growth spurt were statistically significantly shorter than those without this exposure $(163.8 \mathrm{~cm}$ versus $165.5 \mathrm{~cm}$, respectively).

Adult-attained height and postmenopausal BC risk. Table 4 shows the associations between adult-attained height and postmenopausal BC risk overall and by hormone receptor subtypes. Height was associated with a significantly increased risk of postmenopausal $\mathrm{BC}$ overall $\left(\mathrm{HR}_{\text {per }} 5 \mathrm{~cm}=1.07,95 \% \mathrm{CI}\right.$ : 1.01-1.13). In particular, height was positively associated with $\mathrm{ER}+\mathrm{BC}$ risk $\left(\mathrm{HR}_{\text {per }} 5 \mathrm{~cm}=1.08,95 \% \mathrm{CI}: 1.01-1.15\right)$ and, though borderline significant, with $\mathrm{PR}+\mathrm{BC}$ risk $\left(\mathrm{HR}_{\text {per } 5 \mathrm{~cm}}=1.07,95 \% \mathrm{CI}: 0.99-1.16\right)$, but not with ER- BC risk $\left(\mathrm{HR}_{\text {per }} 5 \mathrm{~cm}: 1.03\right.$, 95\% CI: 0.92-1.16) or PR- BC risk $\left(\mathrm{HR}_{\text {per } 5 \mathrm{~cm}}=1.05,95 \% \mathrm{CI}: 0.95-1.16\right)$. Including either BMI or weight, both as additional continuous covariates, in the models for height did not change the associations (data not shown).

Supporting Information Table 1 shows the associations between adult-attained height and postmenopausal $\mathrm{BC}$ risk by combinations of hormone receptor subtypes. Height was only borderline significantly associated with an increased $\mathrm{ER}+\mathrm{PR}+$ $\mathrm{BC}$ risk $\left(\mathrm{HR}_{\text {per }} 5 \mathrm{~cm}=1.07,95 \% \mathrm{CI}: 0.99-1.16\right)$ and an increased $\mathrm{ER}+\mathrm{PR}-\mathrm{BC}$ risk $\left(\mathrm{HR}_{\text {per }} 5 \mathrm{~cm}=1.12,95 \% \mathrm{CI}: 0.99-1.28\right)$, though the number of cases was rather low for other combinations, especially ER-PR+ BC.

Early life energy restriction and postmenopausal $B C$ risk. Table 5 shows the associations between exposure to early life energy restriction and postmenopausal BC risk overall and by hormone receptor subtypes, including stratification on exposure to energy restriction before and/or during the growth spurt versus after the growth spurt. Exposure to energy restriction before and/or during the growth spurt could potentially have an effect on longitudinal growth and, particularly in this group, exposure to energy restriction was associated 


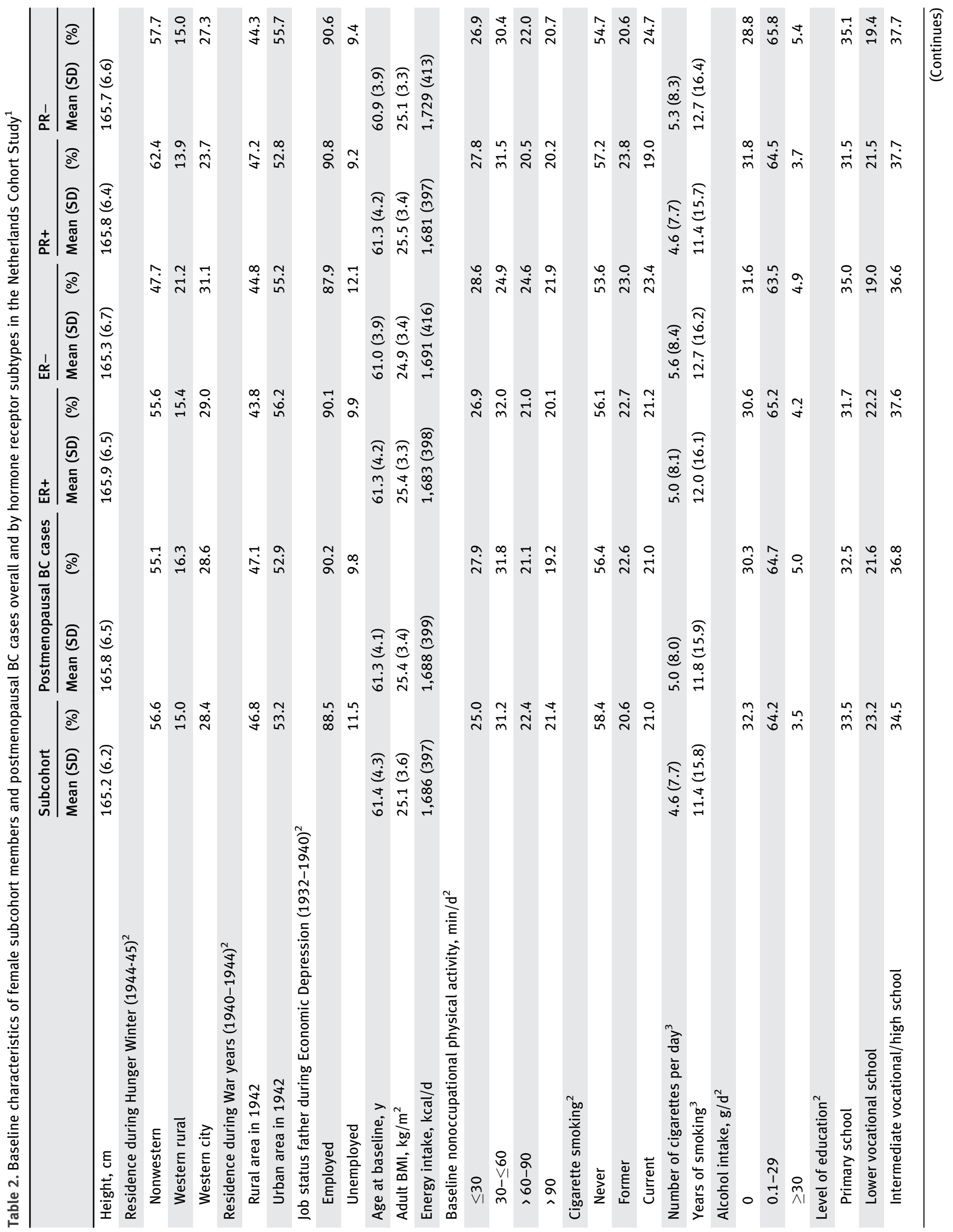




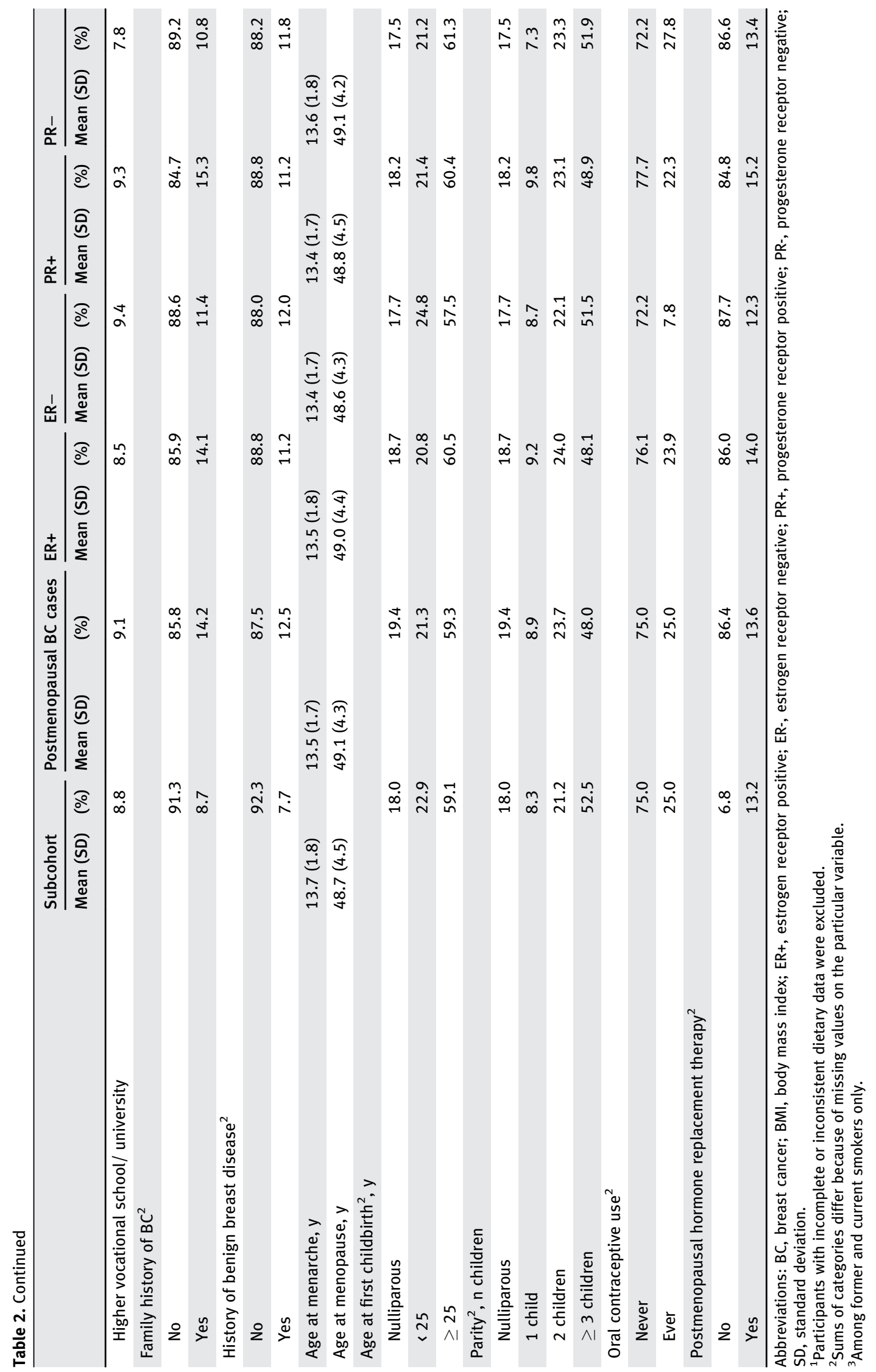


Table 3. Mean and SD of adult-attained height by exposure to early life energy restriction in all female subcohort members in the Netherlands Cohort Study, when restricting to those who were exposed to energy restriction before and/or during the growth spurt ${ }^{1}$, and when additionally restricting to those living in the middle provinces of the Netherlands

\begin{tabular}{|c|c|c|c|c|c|c|}
\hline \multirow[b]{2}{*}{$\begin{array}{l}\text { Proxies for early life energy } \\
\text { restriction }\end{array}$} & \multicolumn{2}{|c|}{ All women } & \multicolumn{2}{|c|}{$\begin{array}{l}\text { Women with energy restriction } \\
\text { before/during the growth spurt }\end{array}$} & \multicolumn{2}{|c|}{$\begin{array}{l}\text { Women with energy } \\
\text { restriction before/during the } \\
\text { growth spurt who lived in the } \\
\text { middle provinces of the } \\
\text { Netherlands }\end{array}$} \\
\hline & $\mathbf{N}$ & $\begin{array}{l}\text { Mean height in } \\
\mathrm{cm}(\mathrm{SD})\end{array}$ & N & $\begin{array}{l}\text { Mean height in } \\
\mathrm{cm} \text { (SD) }\end{array}$ & $\mathrm{N}$ & $\begin{array}{l}\text { Mean height in } \\
\mathrm{cm} \text { (SD) }\end{array}$ \\
\hline \multicolumn{7}{|c|}{$\begin{array}{l}\text { Residence during Hunger Winter } \\
\quad(1944-1945)\end{array}$} \\
\hline Nonwestern & 1,150 & $165.5(6.3)$ & 206 & $165.9(6.6)$ & 44 & $165.0(6.7)$ \\
\hline Western rural & 306 & $165.6(6.0)$ & 57 & $164.9(5.6)$ & 57 & $164.9(5.6)$ \\
\hline Western city & 583 & $165.4(5.8)$ & 108 & $166.5(5.7)$ & 108 & $166.5(5.7)$ \\
\hline $\mathrm{p}$-Value ${ }^{2}$ & & 0.91 & & 0.32 & & 0.18 \\
\hline \multicolumn{7}{|l|}{$\begin{array}{l}\text { Residence during War Years } \\
\quad(1940-44)\end{array}$} \\
\hline Rural area in 1942 & 753 & $165.6(6.0)$ & 267 & $165.4(6.1)$ & 114 & $165.0(5.7)$ \\
\hline Urban area in 1942 & 858 & $165.1(6.0)$ & 294 & $165.5(5.9)$ & 201 & $165.9(5.6)$ \\
\hline$p$-Value ${ }^{2}$ & & 0.11 & & 0.79 & & 0.14 \\
\hline \multicolumn{7}{|l|}{$\begin{array}{l}\text { Job status father during } \\
\text { Economic Depression } \\
\text { (1932-1940) }\end{array}$} \\
\hline Employed & 1,836 & $165.5(6.1)$ & 1,736 & $165.5(6.1)$ & -3 & -3 \\
\hline Unemployed & 240 & $163.6(6.8)$ & 222 & $163.8(6.6)$ & -3 & -3 \\
\hline$p$-Value ${ }^{2}$ & & $<0.0001$ & & 0.0001 & & \\
\hline
\end{tabular}

Abbreviation: SD, standard deviation.

${ }^{1}$ The growth spurt was defined as: 2 years before reported age of menarche till 1 year after reported age of menarche.

${ }^{2}$ Testing for significant differences in mean height between categories of the proxies for early life energy restriction was performed using a t-test in case of two categories and ANOVA in case of more than two categories, with $p<0.05$ considered statistically significant.

${ }^{3}$ For the Economic Depression, the analyses were not restricted to individuals from the middle provinces of the Netherlands as exposure to energy restriction during this time period was not based on place of residence.

with a decreased risk of postmenopausal BC, particularly ER+ $\mathrm{BC}$ and $\mathrm{PR}+\mathrm{BC}$. This result was observed across all three proxies. More specifically, women residing in a western city during the Hunger Winter compared to women residing in a nonwestern area had a significantly decreased risk of ER+ BC and $\mathrm{PR}+\mathrm{BC}(\mathrm{HR}=0.49 ; 95 \% \mathrm{CI}: 0.28-0.88$; $\mathrm{HR}=0.23 ; 95 \%$ CI: $0.10-0.54$, respectively). Women living in an urban area during the War Years compared to women living in a rural area had a (non)significantly decreased risk of $\mathrm{ER}+\mathrm{BC}$ and $\mathrm{PR}+\mathrm{BC}(\mathrm{HR}=0.72 ; 95 \%$ CI: 0.51-1.01; HR $=0.59 ; 95 \%$ CI: $0.39-0.89$, respectively). Women with an unemployed father during the Economic Depression compared to women with an employed father had a nonsignificantly decreased risk of ER+ $\mathrm{BC}$ and $\mathrm{PR}+\mathrm{BC}(\mathrm{HR}=0.89 ; 95 \% \mathrm{CI}: 0.68-1.17 ; \mathrm{HR}=0.76$; 95\% CI: $0.54-1.07$, respectively). The risk of ER- BC was significantly increased for women residing in a western city during the Hunger Winter compared to women residing in a nonwestern area without stratification on timing of exposure to energy restriction in relation to women's growth spurt $(\mathrm{HR}=1.54 ; 95 \%$ CI: 1.11-2.12). This increased risk of ER- BC also seemed independent of whether exposure to energy restriction was before and/or during or after the growth spurt, as both hazard ratios were increased, although the first was not statistically significantly increased $(\mathrm{HR}=1.82 ; 95 \% \mathrm{CI}$ : $0.69-4.78$ and HR $=1.51 ; 95 \%$ CI: $1.06-2.17$, respectively). This nonsignificant finding for women exposed before and/or during the growth spurt may be due to a low number of cases in this subgroup. Except for the association of exposure to energy restriction during the Hunger Winter when exposed after the growth spurt with increased ER- BC risk, no significant associations were observed between exposure to energy restriction after the growth spurt with regard to the other proxies of energy restriction, that is, the War Years and Economic Depression and other subtypes of BC. Additional adjustment for adult-attained height and age at menarche did not change these results (data not shown).

Supporting Information Table 2 shows the associations between exposure to early life energy restriction and postmenopausal BC risk by combinations of hormone receptor subtypes, including stratification on timing of exposure in relation to the growth spurt. Again, when restricting to those women who were exposed to energy restriction before and/or 


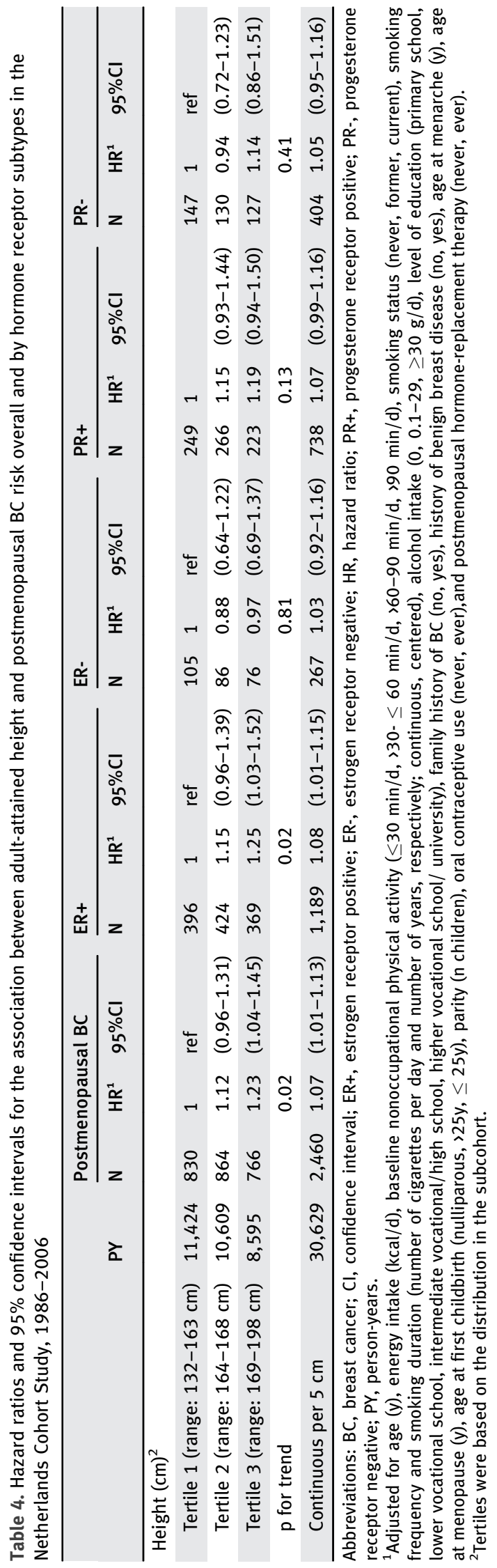

during the growth spurt, the period during which exposure to energy restriction could potentially have had an effect on longitudinal growth, early life energy restriction was (borderline) significantly associated with a decreased risk of $\mathrm{ER}+\mathrm{PR}+\mathrm{BC}$, which was consistently observed across all three proxies $(\mathrm{HR}=0.23$; 95\% CI: $0.10-0.54$ for women living in a western city during the Hunger Winter compared to women residing in a nonwestern area; $\mathrm{HR}=0.60$; 95\% CI: $0.39-0.91$ for women living in an urban area during the War Years compared to women living in a rural area; and $\mathrm{HR}=0.74$; $95 \%$ CI: $0.53-1.04$ for women with an unemployed father during the Economic Depression compared to women with an employed father). The three remaining combinations of hormone receptor subtypes showed no significant associations with any of the energy restriction exposures considered. However, it should be kept in mind that the number of cases was rather low, especially for ER-PR+ BC and ER-PR- BC; resulting in unstable HRs and we refrained from presenting these when the number of cases in the exposure or reference category was less than five.

\section{Discussion}

In our study, height was significantly positively associated with $\mathrm{BC}$ risk, in particular with hormone receptor-positive $\mathrm{BC}$ subtypes. Of the three exposures to energy restriction investigated, that is, exposure to energy restriction during the Economic Depression, War Years, and Hunger Winter, only exposure to energy restriction during the Economic Depression was related to a shorter stature in female subcohort members who were before and/or during their growth spurt, and thus relatively young ( $0-23$ years). Nevertheless, energy restriction during all three periods of exposure provided it occurred before and/or during the growth spurt was associated with a significantly decreased risk of hormone receptor-positive $\mathrm{BC}$ subtypes. Interestingly, exposure to energy restriction during the Hunger Winter was also associated with an increased ER- BC risk, which seemed independent of timing of exposure to energy restriction in relation to women's growth spurt.

In agreement with previous studies, ${ }^{1-3}$ we observed a $7 \%$ increased risk in postmenopausal $\mathrm{BC}$ per $5 \mathrm{~cm}$ increase in adult-attained height. Previously in the NLCS, after 4.3 years of follow-up, the association between adult-attained height and breast cancer risk has also been studied and a positive association was reported, however results were not stratified by hormone receptor-defined subtypes among postmenopausal women. ${ }^{24}$ Regarding hormone receptor status, a recent metaanalysis reported that a positive association between adultattained height and $\mathrm{BC}$ risk was primarily limited to hormone receptor-positive $\mathrm{BC}$, both $\mathrm{ER}+$ and $\mathrm{PR}+\mathrm{BC}$ separately as well as combined $\mathrm{ER}+$ and $\mathrm{PR}+$ status. ${ }^{38} \mathrm{~A}$ borderline significant positive association was observed between adult-attained height and PR- BC. ${ }^{38}$ While this meta-analysis did not distinguish between premenopausal and postmenopausal $\mathrm{BC}$ cases 


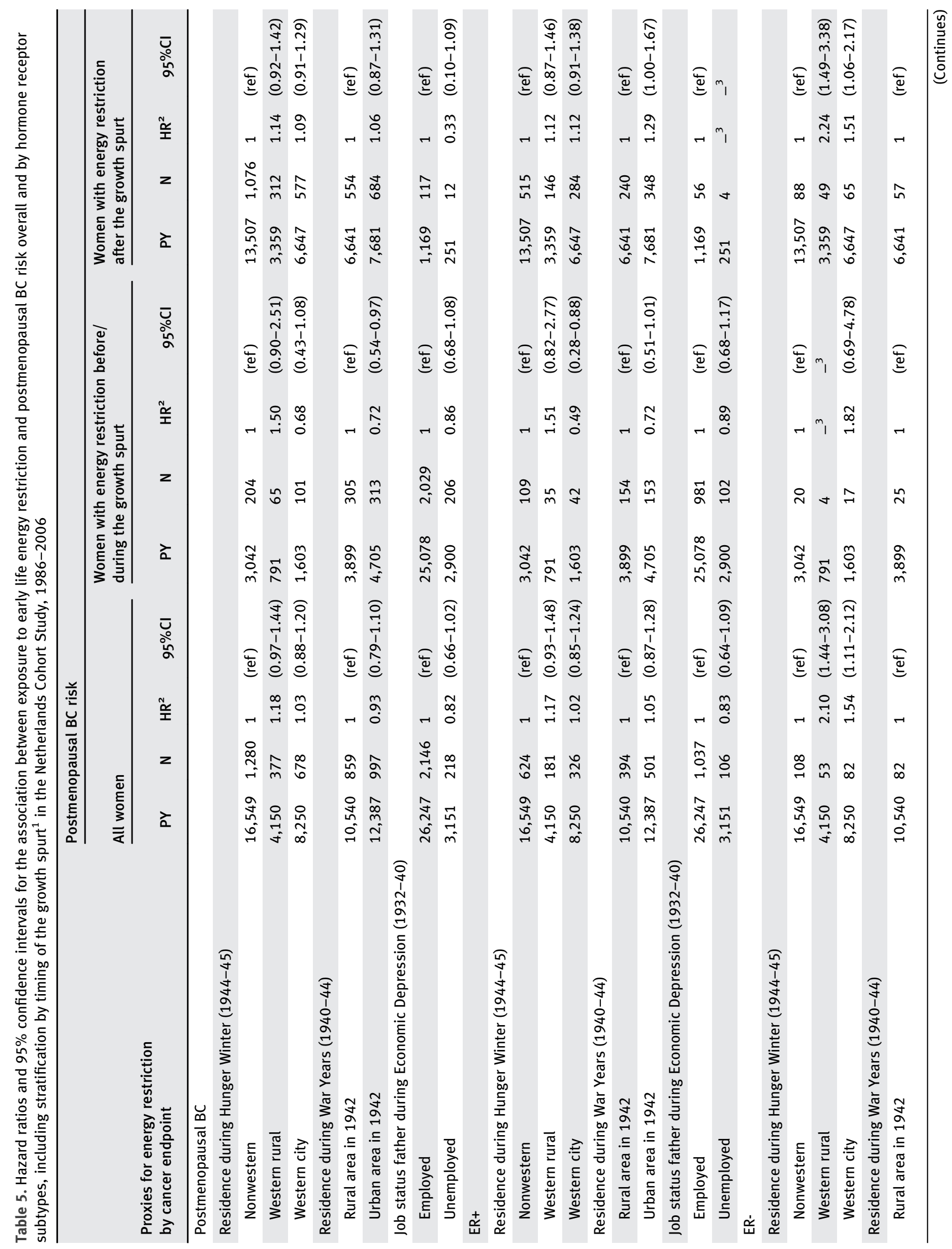




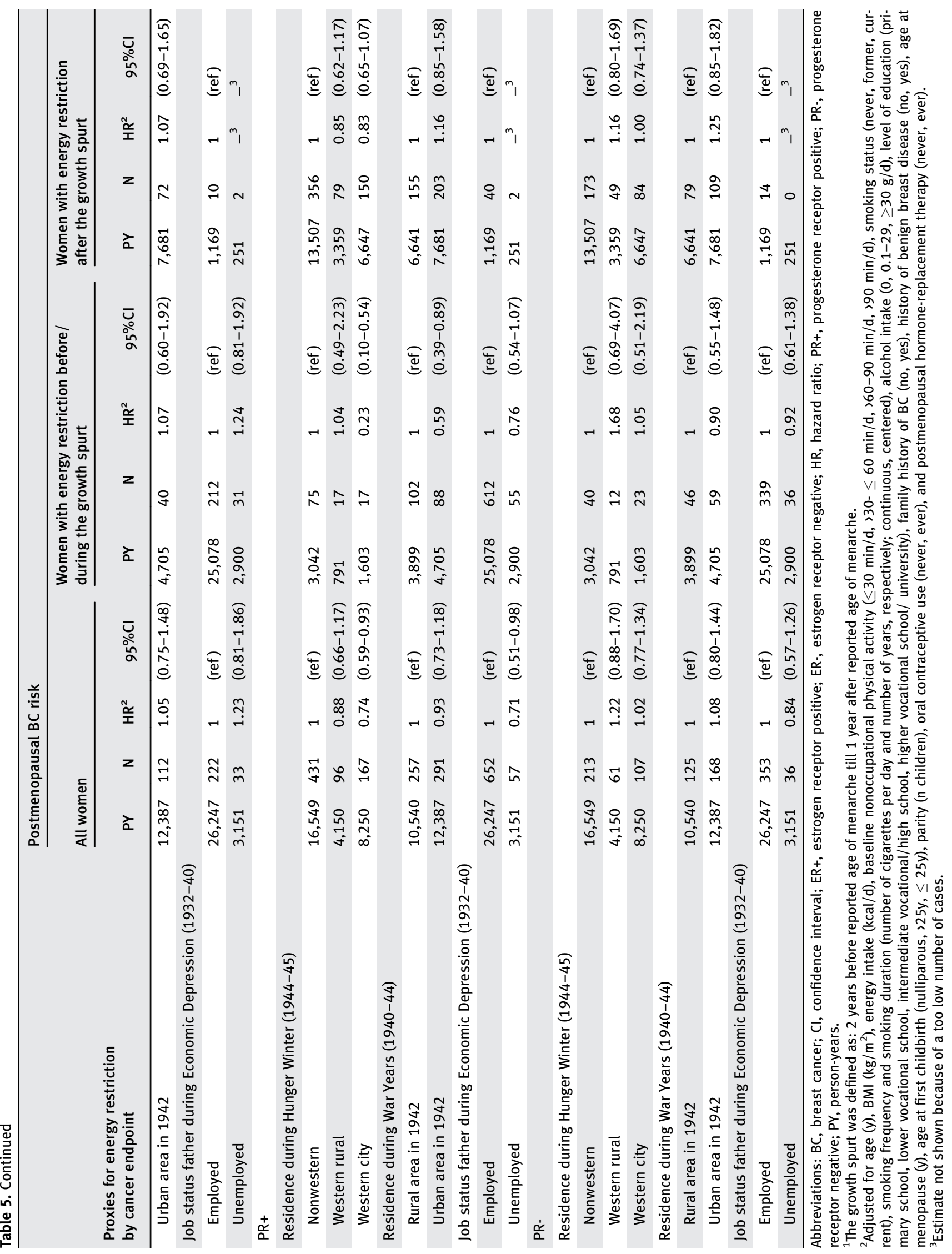


and ER status was only known for $8.7 \%$ of the cases and PR status for $5.4 \%$ of the cases (compared to $59 \%$ and $47 \%$ of the cases, respectively, in our study), it is in support of our finding that adult-attained height may be particularly associated with hormone receptor-positive BC subtypes. Such an association points to the involvement of hormone-related growthmechanisms in the height- $\mathrm{BC}$ association.

Only energy restriction during the Economic Depression before and/or after the growth spurt had an effect on the mean adult-attained height, that is, having an unemployed father during the Economic Depression resulted in a shorter stature compared to having an employed father. Exposure to energy restriction during the Hunger Winter or the War Years before and/or after the growth spurt was not associated with adult-attained height. We had foremost expected an effect of energy restriction on height for energy restriction during the Hunger Winter as this was the most extreme exposure. However exposure to the Hunger Winter, although severe, occurred relatively late in early life and was of relatively short duration, possibly enabling catch-up growth to take place. ${ }^{39}$ The timing of exposure to early life energy restriction may be of importance in relation to it having a potential influence on adult-attained height, as the women were younger ( $0-23$ years) during the Economic Depression as compared to the other exposures (12-28 years during the Hunger Winter and 7-28 years during the War Years).

With regard to energy restriction, previously the NLCS examined the association between early life energy restriction and breast cancer risk after 6.3 years of follow-up and did not observe any associations, neither with regard to the timing of the growth spurt. This may have to do with the lower number of cases. In addition, associations were not examined by hormone receptor-defined subtypes. ${ }^{25}$ In the current study, even though not all proxies of energy restriction influenced adultattained height, all three proxies for energy restriction were associated with a (significantly) decreased risk of ER+ BC and $\mathrm{PR}+\mathrm{BC}$ in women who were exposed to energy restriction before and/or during the growth spurt, the group in which a potential effect on longitudinal growth was expected. The finding that both height and energy restriction, when occurring during a period in life in which adult-attained height is determined, are particularly associated with hormone receptor-positive $\mathrm{BC}$ risk supports the idea that common hormone-related growth-mechanisms may be involved. These findings also underline the notion that timing of exposure to early life energy restriction is an important factor to consider when studying BC risk.

The only study investigating energy restriction in relation to $\mathrm{BC}$ risk by hormone receptor subtypes reported an increased risk of ER-PR- BC, ER-PR+ BC, and ER+PR- BC, particularly in those exposed after birth (aged 0-3 years), while no association was reported for $\mathrm{ER}+\mathrm{PR}+\mathrm{BC}$. It should be noted, however, that the energy restriction (i.e., China's Great famine) was quite extreme in this study as almost everyone experienced severe hunger during this famine and over $3 \%$ of the total population died as a result of the famine. ${ }^{40,41}$ For early life energy restriction during the Hunger Winter, during which many women living in a western city also experienced severe hunger, we also observed an increased ER- BC risk, which seemed independent of timing of exposure to energy restriction with regard to the growth spurt. We speculate on the basis of these findings that this increased risk may in part have to do with the nature of the exposure, as both findings relate to severe energy restriction. Based on animal experimental models, we expected to find a decreased postmenopausal BC risk ${ }^{42}$ that might be dose-dependent, though evidence also exists for a transition phase of the energy restriction effect: there may be a reversal of the effect from an increased to a decreased life- and health span at some level of energy restriction. ${ }^{43,44}$ Energy intake reduction up to $65 \%$ improves the life- and health span in rodents, most noticeably by reducing the incidence of multiple forms of cancer. Yet, it has been suggested that an energy intake reduction of more than $65 \%$ may not impose the same health benefits regarding longevity. ${ }^{13}$ With regard to early life energy restriction in animal models, the number of studies on energy intake reduction of more than $65 \%$ has been limited. The effects of extreme versus more moderate energy restriction on cancer risk are not clear yet but it is possible that the effects may differ with respect to the risk of (subtypes of) postmenopausal BC. However, residual confounding such as stress, ${ }^{45}$ malnutrition and comorbidities related to these severe famines ${ }^{46-48}$ may also be partly responsible for the observed positive associations.

Strengths of the present study include the populationbased prospective design and long follow-up, yielding large case numbers and making selection and information bias unlikely. Importantly, the elaborate available baseline information enabled us to adjust for a large set of relevant confounders, such as a number of reproductive factors, which are relevant for studying associations of adult-attained height and early life energy restriction with postmenopausal BC risk. In addition, information on $\mathrm{ER}+/-$ and $\mathrm{PR}+/-\mathrm{BC}$ status in the NLCS was available for a relatively high percentage of BC cases (59\% and $47 \%$, respectively) and given the relatively large number of cases, we were able to conduct analyses on separate as well as combined $\mathrm{ER}+/$ - and $\mathrm{PR}+/-\mathrm{BC}$ endpoints. Although the number of cases in some subgroup analyses were still small, this is the largest study to-date. We acknowledge that the frequency and method of receptor status testing may have differed over the course of the follow-up. Potential misclassification of the outcome was most likely independent of the exposures studied, and thus may have attenuated results if present. Despite this limitation, that is also not unique to our study, taking into account heterogeneity between hormone receptor subtypes was shown to be of importance given that the observed associations with both adult-attained height 
and early life energy restriction differed for hormone receptor-positive and hormone receptor-negative $\mathrm{BC}$ subtypes. In the meta-analysis by our group, we were only able to investigate the risk of BC overall and observed a $28 \%$ increased BC risk for severe transient early life energy restriction. ${ }^{13}$ Since the distribution of hormone receptor subtypes among BC cases may differ between study populations, and because associations with energy restriction seem to differ for the different BC subtypes, this may have affected the strength and direction of the observed association of early life energy restriction with the risk of $\mathrm{BC}$ overall in our meta-analysis. With regard to early life energy restriction, it should be mentioned that this is a unique exposure available within only a few cohorts worldwide. $^{13}$ Proxy measures were used to estimate energy restriction since information on individual food intake for the NLCS cohort was not available for the three periods of energy restriction, which may have resulted in some exposure misclassification. Nevertheless, any misclassification is likely to be nondifferential, as individuals were still at risk for cancer at baseline when reporting on energy restriction via the proxy measures, which makes attenuation of hazard ratios most likely.

In conclusion, adult-attained height and early life energy restriction before and/or during the growth spurt were both associated with hormone receptor-positive BC risk, in the direction as expected, indicating critical exposure windows for hormonal growth-related mechanisms related to $\mathrm{BC}$.

\section{References}

1. Wirén $\mathrm{S}$, Häggström $\mathrm{C}$, Ulmer $\mathrm{H}$, et al. Pooled cohort study on height and risk of cancer and cancer death. Cancer Causes Control 2014;25: 151-9. https://doi.org/10.1007/s10552-013-0317-7.

2. World Cancer Research Fund / American Institute for Cancer Research. Continuous Update Project Report. Food, Nutrition, Physical Activity, and the Prevention of Breast Cancer. 2010.

3. van den Brandt PA, Spiegelman D, Yaun SS, et al. Pooled analysis of prospective cohort studies on height, weight, and breast cancer risk. Am J Epidemiol 2000;152:514-27.

4. Schönbeck Y, Talma H, van Dommelen P, et al. The world's tallest nation has stopped growing taller: the height of Dutch children from 1955 to 2009. Pediatr Res 2013;73:371-7. https://doi. org/10.1038/pr.2012.189.

5. Cousminer DL, Berry DJ, Timpson NJ, et al. Genome-wide association and longitudinal analyses reveal genetic loci linking pubertal height growth, pubertal timing and childhood adiposity. Hum Mol Genet 2013;22:2735-47. https://doi. org/10.1093/hmg/ddt104.

6. Canchola AJ, Anton-Culver H, Bernstein L, et al. Body size and the risk of postmenopausal breast cancer subtypes in the California teachers study cohort. Cancer Causes Control 2012;23:47385. https://doi.org/10.1007/s10552-012-9897-x.

7. Ritte R, Lukanova A, Tjønneland A, et al. Height, age at menarche and risk of hormone receptorpositive and -negative breast cancer: a cohort study. Int J Cancer 2013;132:2619-29. https://doi. org/10.1002/ijc.27913.

8. Borgquist S, Jirstrom K, Anagnostaki L, et al. Anthropometric factors in relation to different tumor biological subgroups of postmenopausal breast cancer. Int J Cancer 2009;124: 402-11. https://doi.org/10.1002/ijc.23850.

9. Fagherazzi G, Vilier A, Boutron-Ruault MC, et al. Height, sitting height, and leg length in relation with breast cancer risk in the E3N cohort. Cancer Epidemiol Biomarkers Prev 2012;21: 1171-5. https://doi.org/10.1158/1055-9965.EPI12-0130.

10. Bertrand KA, Gerlovin H, Bethea TN, et al. Pubertal growth and adult height in relation to breast cancer risk in African American women. Int J Cancer 2017;141:2462-70. https://doi.org/10. 1002/ijc.31019.
11. Ruder EH, Dorgan JF, Kranz S, et al. Examining breast cancer growth and lifestyle risk factors: early life, childhood, and adolescence. Clin Breast Cancer 2008;8:334-42. https://doi.org/10.3816/ CBC.2008.n.038.

12. Okasha M, McCarron P, Gunnell D, et al. Exposures in childhood, adolescence and early adulthood and breast cancer risk: a systematic review of the literature. Breast Cancer Res Treat 2003;78:223-76.

13. Elands RJ, Simons CC, van Dongen M, et al. A systematic literature review and metaregression analysis on early-life energy restriction and cancer risk in humans. Plos One 2016;11: e0158003. https://doi.org/10.1371/journal.pone. 0158003.

14. Elias SG, Keinan-Boker L, Peeter EH, et al. Long term consequences of the 1944-1945 Dutch famine on the insulin-like growth factor axis. Int $J$ Cancer 2004;108:628-30. https://doi.org/10.1002/ ijc.11584.

15. Dahlmann N, Petersen K. Influences of environmental conditions during infancy on final body stature. Pediatr Res 1977;11:695-700. https://doi. org/10.1203/00006450-197705000-00014.

16. Angell-Andersen E, Tretli S, Bjerknes R, et al. The association between nutritional conditions during world war II and childhood anthropometric variables in the Nordic countries. Ann Hum Biol 2004;31:342-55. https://doi.org/10. 1080/03014460410001685304.

17. Brundtland GH, Liestol K, Walloe L. Height, weight and menarcheal age of Oslo schoolchildren during the last 60 years. Ann Hum Biol 1980;7: 307-22.

18. Nilsen TI, Vatten LJ. Adult height and risk of breast cancer: a possible effect of early nutrition. Br J Cancer 2001;85:959-61. https://doi.org/10. 1038/sj.bjc.6691946.

19. Li CI, Littman AJ, White E. Relationship between age maximum height is attained, age at menarche, and age at first full-term birth and breast cancer risk. Cancer Epidemiol Biomarkers Prev 2007;16: 2144-9. https://doi.org/10.1158/1055-9965.EPI07-0242.

20. Ahlgren M, Melbye M, Wohlfahrt J, et al. Growth patterns and the risk of breast cancer in women. N Engl J Med 2004;351:1619-26. https://doi. org/10.1056/NEJMoa040576.
21. Velie EM, Nechuta S, Osuch JR. Lifetime reproductive and anthropometric risk factors for breast cancer in postmenopausal women. Breast Dis 2005;24:17-35.

22. De Stavola BL, dos Santos Silva I, McCormack V, et al. Childhood growth and breast cancer. Am J Epidemiol 2004;159:671-82.

23. Alimujiang A, Mo M, Liu Y, et al. The association between China's great famine and risk of breast cancer according to hormone receptor status: a hospital-based study. Breast Cancer Res Treat 2016;160:361-9. https://doi.org/10.1007/ s10549-016-3994-6.

24. van den Brandt PA, Dirx MJ, Ronckers CM, et al. Height, weight weight change, and postmenopausal breast cancer risk: The Netherlands cohort study. Cancer Causes Control 1997;8:39-47.

25. Dirx MJ, van den Brandt PA, Goldbohm RA, et al. Diet in adolescence and the risk of breast cancer: results of The Netherlands cohort study. Cancer Causes Control 1999;10:189-99.

26. van den Brandt PA, Goldbohm RA, Van 'T Veer $\mathrm{P}$, et al. A large-scale prospective cohort study on diet and cancer in The Netherlands. $J$ Clin Epidemiol 1990;43:285-95.

27. Goldbohm RA, van den Brandt PA, Dorant E. Estimation of the coverage of Dutch municipalities by cancer registries and PALGA based on hospital discharge data. Tijdschr Soc Gezondheidsz 1994;72:80-4.

28. Casparie M, Tiebosch AT, Burger G, et al. Pathology databanking and biobanking in The Netherlands, a central role for PALGA, the nationwide histopathology and cytopathology data network and archive. Cell Oncol 2007;29: 19-24.

29. Burger GSH, Drummond J. Malnutrition and starvation in Western Netherlands, September 1944 to July 1945. Part I and II. The Hague, the Netherlands: General State Printing Office 1948.

30. Trienekens G Tussen ons volk en de honger. De voedelvoorziening, 1940-45. (English translation: Between our nation and the hunger. The food supply, 1940-45). Utrecht, the Netherlands: Stichting Matrijs (1985).

31. Breunis J The Annals of the American Academy of Political and Social Science, Vol. 245, The Netherlands during German Occupation (May, 1946), pp. 87-92. 
32. Paternoster L, Howe LD, Tiling K, et al. Adult height variants affect birth length and growth rate in children. Hum Mol Genet 2011;20:4069-75. https://doi.org/10.1093/hmg/ddr309.

33. Schouten LJ, van Dijk BA, Lumey LH, et al. Energy restriction during childhood and early adulthood and ovarian cancer risk. Plos One 2011;6:e27960. https://doi.org/10.1371/journal. pone.0027960.

34. Barlow WE. Robust variance estimation for the case-cohort design. Biometrics 1994;50:1064-72.

35. Schoenfeld D. Partial residuals for the proportional hazards regression model. Biometrika 1982; 69:239-41.

36. Sperrin M, Marshall AD, Higgins V, et al. Body mass index relates weight to height differently in women and older adults: serial cross-sectional surveys in England (1992-2011). J Public Health (Oxf) 2016;38:607-13. https://doi.org/10.1093/ pubmed/fdv067.

37. Drøyvold WB, Nilsen TI, Krüger O, et al. Change in height, weight and body mass index: longitudinal data from the HUNT study in Norway. Int $J$
Obes (Lond) 2006;30:935-9. https://doi.org/10. 1038/sj.ijo.0803178.

38. Zhang B, Shu O, Delahanty RJ, et al. Height and breast cancer risk: evidence from prospective studies and Mendelian randomization. J Natl Cance Inst 2015;107:1-17. https://doi.org/10.1093/jnci/ djv219.

39. Widén E, Ripatti S, Cousminer DL, et al. Distinct variants at LIN28B influence growth in height from birth to adulthood. Am J Hum Genet 2010; 86:773-82. https://doi.org/10.1016/j.ajhg.2010. 03.010 .

40. Kane P. The demography of famine. Genus 1987 ; 43:43-58.

41. Song S. Mortality consequences of the 1959-1961 great leap forward famine in China: debilitation, selection, and mortality crossovers. Soc Sci Med 2010;71:551-8. https://doi.org/10.1016/j. socscimed.2010.04.034.

42. Dirx MJ, Zeegers MP, Dagnelie PC, et al. Energy restriction and the risk of spontaneous mammary tumors in mice: a meta-analysis. Int J Cancer 2003; 106:766-70. https://doi.org/10.1002/ijc.11277.
43. Roberts SB, Speakman J. Update on human calorie restriction research. Adv Nutr 2013;4:563-4. https://doi.org/10.3945/an.113.004317.

44. Speakman JR, Mitchell SE. Caloric restriction. Mol Aspects Med 2011;32:159-221. https://doi. org/10.1016/j.mam.2011.07.001.

45. Vin-Raviv N, Dekel R, Barchana M, et al. World war II-related post-traumatic stress disorder and breast cancer risk among Israeli women: a casecontrol study. Int Psychogeriatr 2014;26:499-508. https://doi.org/10.1017/S1041610213002081.

46. Bercovich E, Keinan-Boker L, Shasha SM. Longterm health effects in adults born during the holocaust. Isr Med Assoc J 2014;16:203-7.

47. Koupil I, Shestov DB, Sparén P, et al. Blood pressure, hypertension and mortality from circulatory disease in men and women who survived the siege of Leningrad. Eur J Epidemiol 2007;22:223-34. https://doi.org/10.1007/s10654-007-9113-6.

48. Huang C, Li Z, Wang M, et al. Early life exposure to the 1959-1961 Chinese famine has long-term health consequences. J Nutr 2010;140:1874-8. https://doi.org/10.3945/jn.110.121293. 